\title{
PROTOTIPE PENENTU SUDUT ELEVASI LENGAN MERIAM SECARA NIRKABEL MENGGUNAKAN MOTOR LANGKAH BERBASIS MIKROKONTROLER
}

\section{PROTOTYPE OF ELEVATION ANGLE SET WIRELESS ARM USING MICROCONTROLLER BASED STEP MOTOR}

\author{
Endang Rosdiana ${ }^{1}$, Rahmat Awaludin Salam ${ }^{1}$, Reza Fauzi Iskandar ${ }^{1}$, Dudi \\ Darmawan', Ahmad Marjan², Octo Emerald Siregar², Melina Melina², Vivien \\ Restianim $^{3}$, Dewi Novianti ${ }^{4}$, Valentina Adimurti Kusumaningtyas ${ }^{2}$ \\ ${ }^{1}$ Program studi Teknik Fisika, Fakultas Teknik Elektro,Telkom University \\ ${ }^{2}$ Fakultas Sains dan Informatika,Universitas Jenderal Achmad Yani \\ ${ }^{3}$ Program Studi Teknik Sipil, Fakultas Teknik, Universitas Flores \\ ${ }^{4}$ Program Studi Matematika, Fakultas Teknik, Universitas Samudra \\ endangr@telkomuniversity.ac.id
}

\begin{abstract}
Problems that usually arise in gun arm control are the lack of accuracy of the angle formed and the safety factor of the gun operator itself. By designing a computer-based control system that can calculate accurately and quickly, and utilize wireless technology, this problem can be overcome. The prototype made is quite simple, consisting of a computer with Bluetooth installed, a bluetooth module, a microcontroller, a stepper motor and an electric circuit driving a stepper motor. Step motors are used to drive mechanical systems either vertically or horizontally. From the measurement data, the characteristics of this tool are obtained, namely the vertical angle accuracy is better when the elevation angle exceeds $14.5^{\circ}$, while the horizontal angle accuracy is smaller when the elevation angle exceeds $180^{\circ}$. For tool precision, the vertical angle has an uncertainty value of 0 so that for repetitions with the same conditions the same value is obtained, while for the horizontal angle the uncertainty value will be greater when the elevation angle is more than $180^{\circ}$. This prototype works quite well with the maximum distance between the computer and the stepper motor 7 meters without any barrier media, with no effect on the elevation angle formed.
\end{abstract}

Keywords: Bluetooth, Microcontroller, Stepper Motor.

\begin{abstract}
ABSTRAK
Permasalahan yang biasa timbul pada pengendalian lengan meriam adalah kurangnya akurasi sudut yang terbentuk dan faktor keamanan dari operator meriam itu sendiri. Dengan mendisain suatu sistem kendali berbasis komputer yang dapat menghitung dengan teliti dan cepat, serta memanfaatkan teknologi nirkabel permasalahan itu dapat diatasi. Prototipe yang dibuat ini cukup sederhana, terdiri dari komputer dengan Bluetooth terpasang, modul bluetooth, mikrokontroler, motor langkah dan rangkaian elektrik penggerak motor langkah. Motor langkah digunakan untuk menggerakkan sistem mekanis baik secara vertikal maupun horizontal. Dari data pengukuran diperoleh karakteristik alat ini yaitu akurasi sudut vertikal lebih baik saat sudut elevasi melebihi $14.5^{\circ}$, sedangkan akurasi sudut horizontal lebih kecil saat sudutelevasi melebihi $180^{\circ}$, untuk tingkat kepresisian alat, sudut vertikal memiliki nilai ketidakpastian 0 sehingga untuk pengulangan dengan kondisi yang sama diperoleh nilai yang sama, sedangkan untuk sudut horizontal nilai ketidakpastian akan semakin besar saat sudut elevasi lebih dari $180^{\circ}$. Prototipe ini bekerja cukup baik dengan jarak maksimum antara komputer dan motor langkahnya 7 meter tanpa ada media penghalang, dengan tidak mempengaruhi sudut elevasi yang terbentuk.
\end{abstract}

Kata Kunci: Bluetooth, Microcontroller, Stepper Motor.

\section{PENDAHULUAN}

Pengaturan arah atau sudut tembakan melalui lengan meriam merupakan hal penting dalam pengoperasian suatu meriam. Hal tersebut dikarenakan pengaturan arah 
sangat erat kaitannya dengan lokasi jatuhnya peluru terhadap target (Halliday et al., 2010). Semakin presisi pengarahan lengan meriam, semakin presisi pula peluru menyasar target. Akan tetapi, pengendalian lengan meriam yang masih dilakukan secara manual, memungkinkan adanya penurunan tingkat akurasi yang dimiliki oleh peluru. Selain itu, pengoperasian dari jarak dekat mengakibatkan rentannya operator meriam terhadap kecelakaan yang diakibatkan oleh gaya reaksi dari ledakan meriam (Halliday et al., 2010).

Sebagai upaya menanggulangi tingkat kegagalan hasil tembakan akibat ketidakakuratan penentuan arah laras meriam serta kerentanan operator terhadap kecelakaan, suatu sistem kendali jarak jauh perlu untuk diterapkan (Ogata, 2001). Terdapat banyak jenis sistem kendali yang telah diterapkan untuk berbagai kebutuhan (Ogata, 2001; Salam et al., 2019). Diantara sistemsistem kendali tersebut, sistem kendali loop terbuka memberikan kemudahan pada proses pengontrolannya (Ogata, 2001). Di lain pihak, proses pengendalian jarak jauh dari sistem meriam dapat dilakukan dengan menggunakan teknologi nirkabel (Morris, 2001). Tidak hanya untuk menanggulangi kerentanan operator, pemberian teknologi nirkabel ini juga dapat digunakan untuk mengondisikan tingkat kegagalan meriam akibat kerusakan kabel dan lain sebagainya. Oleh karena itu, suatu sistem kendali jarak jauh berbasis teknologi nirkabel perlu untuk diterapkan pada sistem lengan meriam.

Pada penelitian ini, sebuah prototipe penentu sudut elevasi lengan meriam telah dikembangkan secara nirkabel. Pergerakan lengan meriam akan diatur menggunakan sistem kendali loop terbuka dengan pengendalian jarak jauh dilakukan menggunakan teknologi bluetooth. Detail pembuatan sistem beserta hasilnya akan dijelaskan secara terperinci pada bagian berikutnya.

\section{METODE \\ PERANCANGAN ALAT \\ Rancang Bangun Sistem}

Rancang bangun sistem dalam penelitian ini ditunjukkan oleh diagram blok pada gambar 1. Dalam sistem ini, input yang digunakan adalah kecepatan awal peluru, jarak target dan sudut horizontal. Input tersebut diolah oleh program aplikasi yang dibuat pada Visual Studio yang mana keluaran dari aplikasi tersebut berupa sudut vertikal dan sudut horizontal lengan meriam. Keluaran tersebut dikirim secara nirkabel melalui Bluetooth ke rangkaian Bluetooth Interface Module (DBM-01) yang terhubung secara serial dengan mikrokontroler AT89S51.

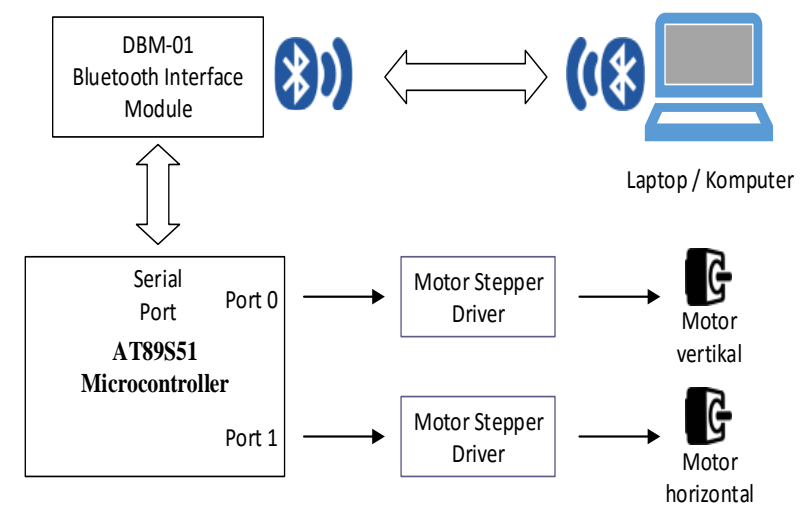

Gambar 1. Blok Diagram Sistem

Nilai sudut elevasi yang diterima oleh mikrokontroler selanjutnya diolah untuk dijadikan sebagai perintah pada motor langkah melalui Port 0 dan Port 1 . Masing-masing motor akan menggerakkan mekanisme lengan meriam sedemikian rupa sehingga lengan meriam dapat membentuk sudut vertikal dan horizontal sesuai dengan keluaran program aplikasi pada komputer(Ruifeng et al., 2015).

\section{Perencanaan Mekanisme Meriam}

Mekanisme pergerakan lengan meriam ini menggunakan sistem perputaran roda 
gigi sebanyak dua tingkat (termasuk roda gigi pada motor langkah). Motor langkah yang digunakan memiliki sudut $1,8^{\circ}$ per langkah, yang dengan mode half step akan menghasilkan resolusi sudut $0,9^{\circ}$ per langkahnya. Pada pembuatan prototipe ini akan menggunakan mode half step. Namun, untuk jumlah 400 step dirasakan kurang teliti, oleh karena itu digunakan perbandingan jumlah gir sebesar 1 : 9 dari poros motor terhadap pergerakan lengan meriam dengan menggunakan gir. sehingga diharapkan didapat akurasi sudut $0,1^{0}$ pada lengan meriam. Prototipe sistem lengan yang dibangun, ditunjukkan oleh gambar 2.

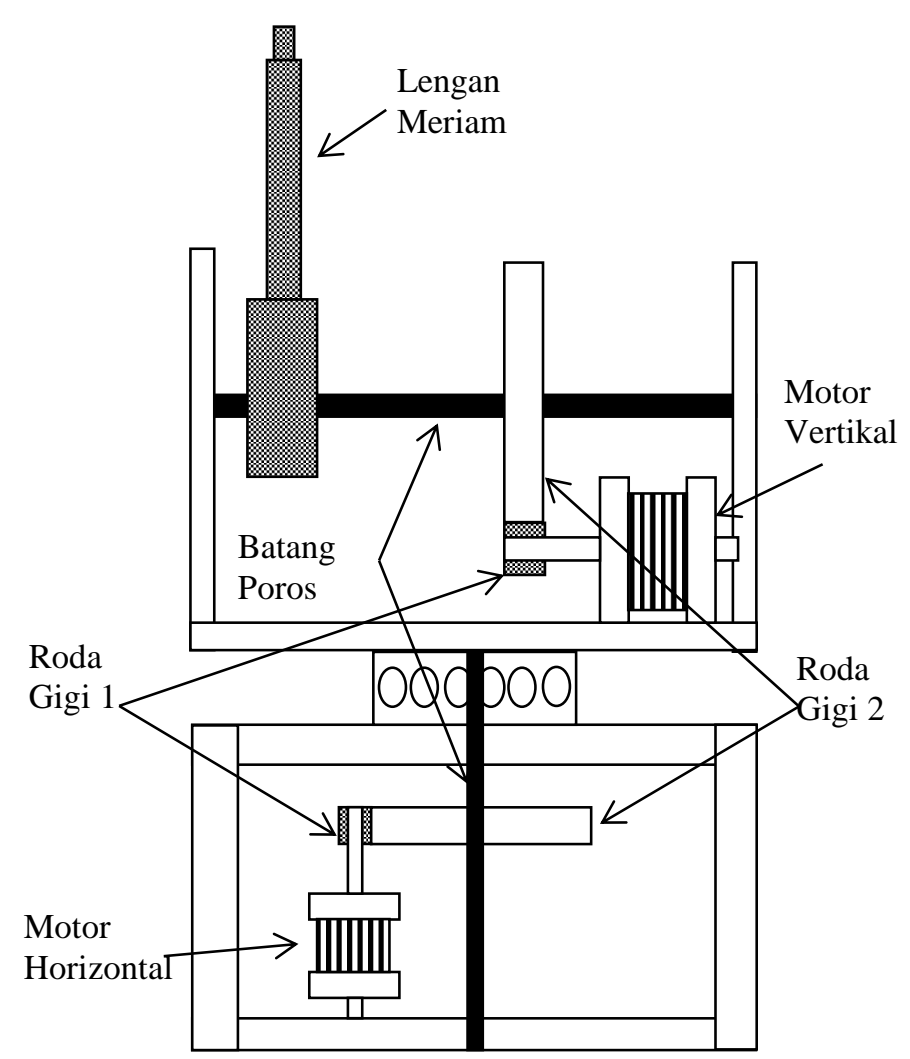

Gambar 2. Mekanisme Lengkap Prototipe Meriam Artileri

\section{Rancang Bangun Perangkat Keras} dan Lunak

Perancangan perangkat keras terdiri dari pembuatan rangkaian elektronika yang teridiri dari rangkaian minimum AT89S51 dan rangkaian switching transistor sebagai penggerak motor langkah. Sedangkan untuk mekanisme lengan meriam meliputi pemilihan bahan, fabrikasi sasis dan gear kemudian perangkaian. Pada bagian perangkat lunak terdiri dari pemrograman assembly untuk mikrokontroler AT89S51 dan pemrograman berorientasi obyek (OOP) untuk program aplikasi di komputer menggunakan Visual Studio (Wu \& Zhang, 2017). Data pengukuran sudut Lengan Meriam akan disimpan dalam suatu Database MySQL merupakan suatu perangkat lunak database yang berbentuk database relasional atau disebut Relational Database Management System yang menggunakan suatu bahasa perintah yang bernama SQL (Structured Query Language ) (Melina et al., 2020).

Rangkaian penggerak sebagai-mana ditunjukkan oleh gambar 3 digunakan untuk menjembatani antara output mikrokontroler dengan motor langkah. Rangkaian ini diperlukan karena arus keluaran dari mikrokontroler tidak mampu untuk menggerakkan motor langkah (Liu dan Dong, 2015).

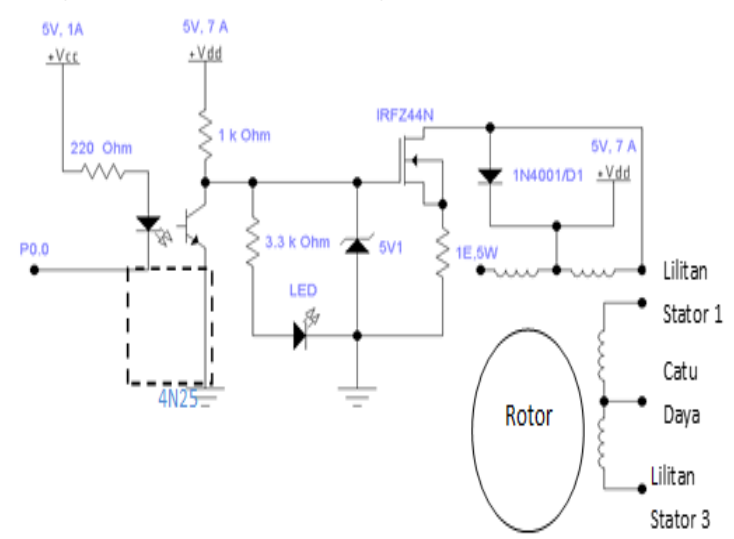

Gambar 3. Rangkaian Penggerak

\section{HASIL DAN PEMBAHASAN}

Setelah semua koneksi perangkat keras dan sistem mekanis meriam dipersiapkan, maka langkah selanjutnya adalah menjalankan aplikasi lengan meriam. Tampilan aplikasi ini 
ditunjukkan oleh gambar gambar 4 . Terdapat dua bagian yang diatur pada sistem ini, yakni sudut vertikal, dan sudut horizontal. Sudut vertikal dikondisikan untuk mengatur arah tegak dari laras meriam sehingga pada kondisi ini dibatasi hanya dari $0^{\circ}$ hingga $180^{\circ}$, adapun sumbu horizontal dikondisikan dapat bergerak dalam satu putaran penuh.

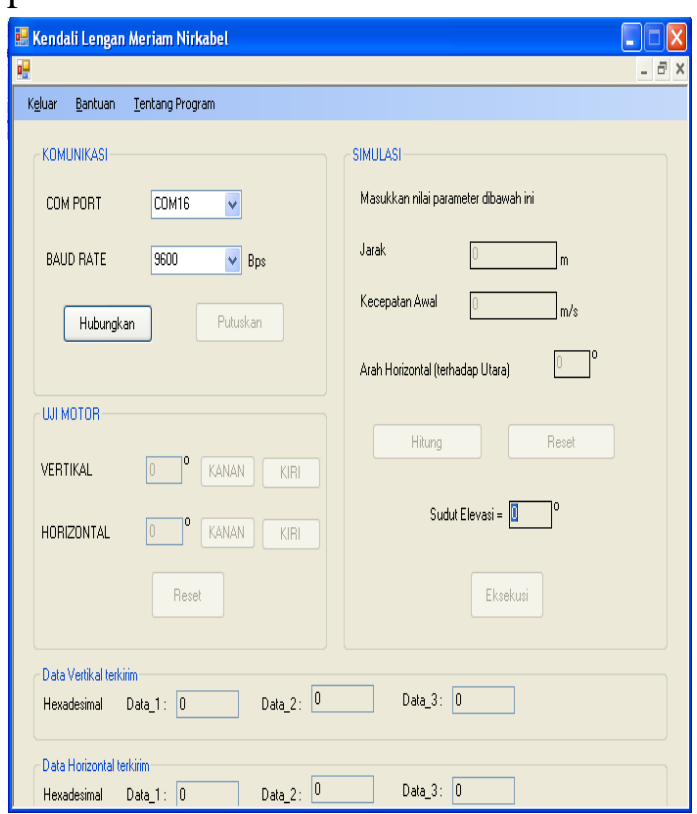

Gambar 4. Tampilan Aplikasi Kendali Lengan Meriam

Adapun hasil pengukuran sudut vertikal dan sudut horizontal dapat dilihat pada tabel 1 dan 2, secara berurutan. Pada kondisi ini, kecepatan awal peluru dikondisikan $600 \mathrm{~m} / \mathrm{s}$, yang merupakan nilai kecepatan awal standar untuk meriam artileri, dengan nilai jarak yang dikondisikan bervariasi. Percobaan dilakukan sebanyak lima kali untuk melihat tingkat akurasi dan presisi yang dimiliki oleh sistem prototipe laras meriam yang dikembangkan.
Tabel 1. Pengukuran sudut Lengan Meriam untuk Kecepatan awal $600 \mathrm{~m} / \mathrm{s}$

\begin{tabular}{|c|c|c|c|c|c|c|c|c|c|c|}
\hline \multirow{2}{*}{ No } & \multirow{2}{*}{$\begin{array}{c}\text { Kecepatan } \\
\text { Awal } \\
\text { Peluru vo } \\
(\mathrm{m} / \mathrm{s})\end{array}$} & \multirow{2}{*}{$\begin{array}{l}\text { Jarak } \\
\text { Target } \\
s(m)\end{array}$} & \multirow{2}{*}{$\begin{array}{c}\text { Suduthasil } \\
\text { perhitungan } \\
\alpha(\odot)\end{array}$} & \multicolumn{5}{|c|}{$\begin{array}{l}\text { Sudut terbentuk ( } \alpha \text { ) Pada } \\
\text { Pengukuran ke- }\end{array}$} & \multirow{2}{*}{$\begin{array}{c}\text { Rata-rata } \\
\text { sudut } \\
\text { terbentuk } \\
a\end{array}$} & \multirow{2}{*}{ bias } \\
\hline & & & & $I$ & II & $I I I$ & $I V$ & $V$ & & \\
\hline 1 & 600 & 500 & 0.4 & 0.5 & 0.5 & 0.5 & 0.5 & 0.5 & 0.5 & 0.1 \\
\hline 2 & 600 & 1000 & 0.8 & 0.5 & 0.5 & 0.5 & 0.5 & 0.5 & 0.5 & -0.3 \\
\hline 3 & 600 & 2500 & 2.0 & 2.0 & 2.0 & 2.0 & 2.0 & 2.0 & 2.0 & 0.01 \\
\hline 4 & 600 & 4000 & 3.2 & 3.5 & 3.5 & 3.5 & 3.5 & 3.5 & 3.5 & 0.3 \\
\hline 5 & 600 & 5500 & 4.4 & 4.5 & 4.5 & 4.5 & 4.5 & 4.5 & 4.5 & 0.1 \\
\hline 6 & 600 & 7000 & 5.6 & 6.0 & 6.0 & 6.0 & 6.0 & 6.0 & 6.0 & 0.4 \\
\hline 7 & 600 & 8500 & 6.8 & 7.0 & 7.0 & 7.0 & 7.0 & 7.0 & 7.0 & 0.2 \\
\hline 8 & 600 & 10000 & 8.1 & 8.5 & 8.5 & 8.5 & 8.5 & 8.5 & 8.5 & 0.4 \\
\hline 9 & 600 & 11500 & 9.3 & 9.5 & 9.5 & 9.5 & 9.5 & 9.5 & 9.5 & 0.2 \\
\hline 10 & 600 & 13000 & 10.6 & 11.0 & 11.0 & 11.0 & 11.0 & 11.0 & 11.0 & 0.4 \\
\hline 11 & 600 & 14500 & 11.9 & 12.0 & 12.0 & 12.0 & 12.0 & 12.0 & 12.0 & 0.1 \\
\hline 12 & 600 & 16000 & 13.2 & 13.5 & 13.5 & 13.5 & 13.5 & 13.5 & 13.5 & 0.3 \\
\hline 13 & 600 & 17500 & 14.5 & 14.5 & 14.5 & 14.5 & 14.5 & 14.5 & 14.5 & -0.04 \\
\hline 14 & 600 & 19000 & 15.9 & 16.0 & 16.0 & 16.0 & 16.0 & 16.0 & 16.0 & 0.07 \\
\hline 15 & 600 & 20500 & 17.4 & 17.5 & 17.5 & 17.5 & 17.5 & 17.5 & 17.5 & 0.1 \\
\hline 16 & 600 & 22000 & 18.8 & 19.0 & 19.0 & 19.0 & 19.0 & 19.0 & 19.0 & 0.2 \\
\hline 17 & 600 & 23500 & 20.4 & 20.5 & 20.5 & 20.5 & 20.5 & 20.5 & 20.5 & 0.1 \\
\hline 18 & 600 & 25000 & 22.0 & 22.0 & 22.0 & 22.0 & 22.0 & 22.0 & 22.0 & 0.01 \\
\hline 19 & 600 & 26500 & 23.7 & 23.5 & 23.5 & 23.5 & 23.5 & 23.5 & 23.5 & -0.2 \\
\hline 20 & 600 & 28000 & 25.5 & 25.5 & 25.5 & 25.5 & 25.5 & 25.5 & 25.5 & -0.03 \\
\hline 21 & 600 & 29500 & 27.5 & 27.5 & 27.5 & 27.5 & 27.5 & 27.5 & 27.5 & -0.01 \\
\hline 22 & 600 & 31000 & 29.7 & 30.0 & 30.0 & 30.0 & 30.0 & 30.0 & 30.0 & 0.3 \\
\hline 23 & 600 & 32500 & 32.3 & 32.5 & 32.5 & 32.5 & 32.5 & 32.5 & 32.5 & 0.2 \\
\hline 24 & 600 & 34000 & 35.4 & 35.5 & 35.5 & 35.5 & 35.5 & 35.5 & 35.5 & 0.09 \\
\hline 25 & 600 & 35500 & 40.2 & 40.0 & 40.0 & 40.0 & 40.0 & 40.0 & 40.0 & -0.2 \\
\hline 26 & 600 & 36000 & 45.0 & 45.0 & 45.0 & 45.0 & 45.0 & 45.0 & 45.0 & 0.00 \\
\hline
\end{tabular}

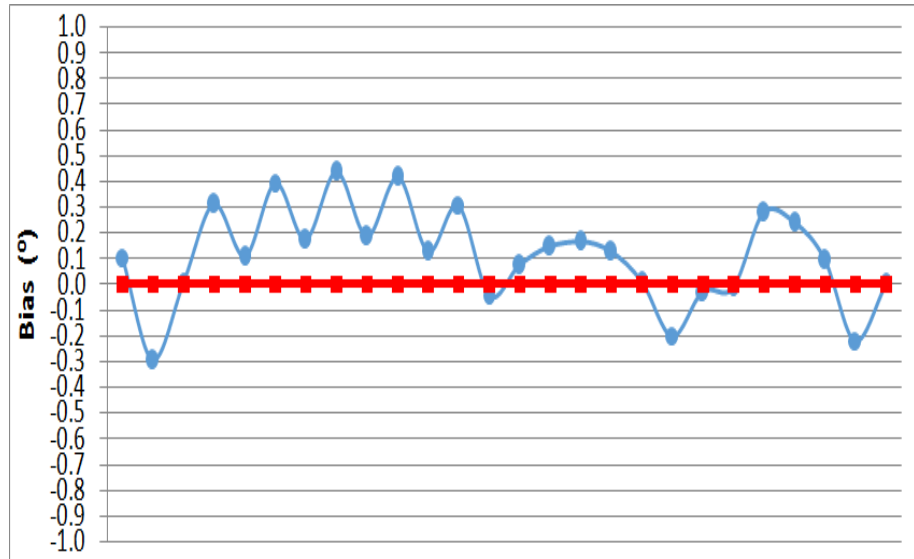

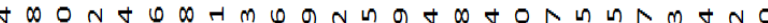

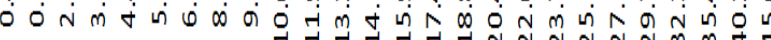
$\rightarrow$ bias $\left({ }^{\circ}\right) \quad$ Sudut Vertikal hasil perhitungan $\left({ }^{\circ}\right)$

Gambar 5. Grafik Bias Untuk Sudut Vertikal 
Tabel 2. Pengukuran Sudut Horizontal

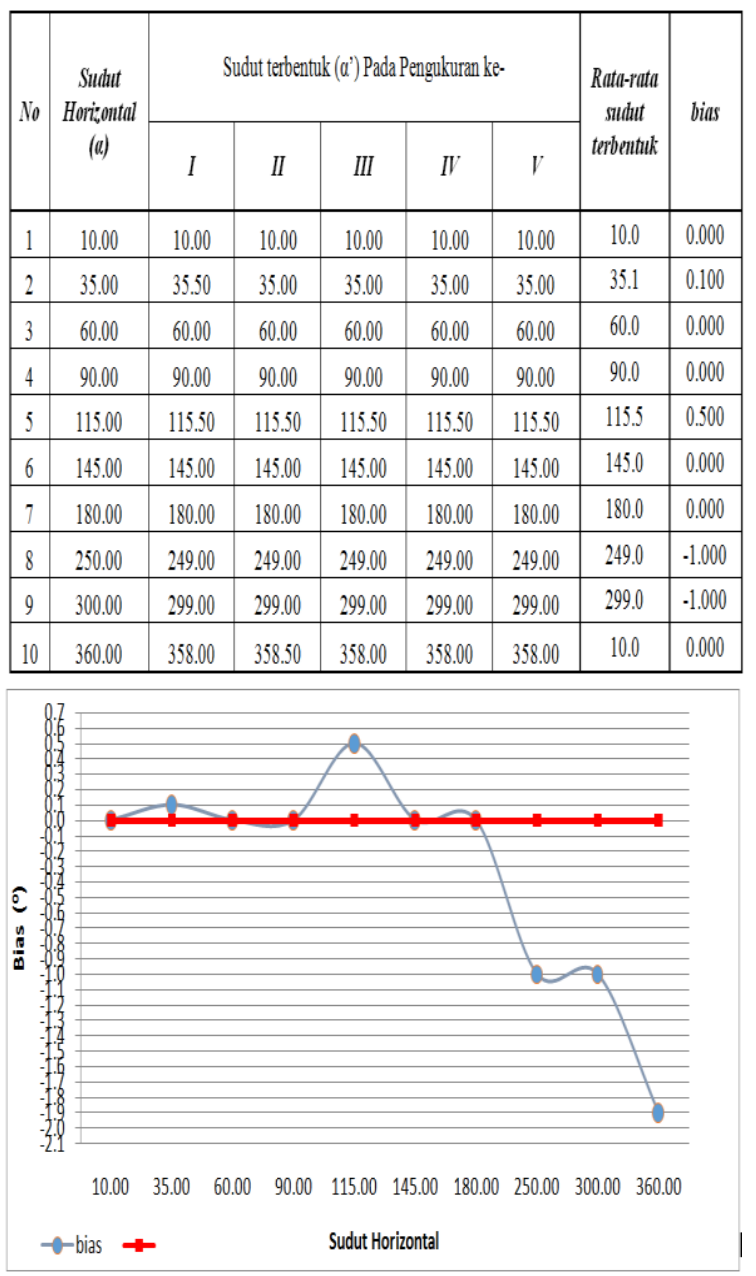

Gambar 6. Grafik bias untuk sudut horizontal

Dari hasil pengukuran yang dilakukan secara berulang dengan rentang sudut antara $0-45^{\circ}$ untuk sudut vertikal dan $0-360^{\circ}$ untuk sudut horizontal, dapat dilihat berdasarkan gambar 5 dan 6, bahwa alat yang dibuat dapat membentuk sudut dengan baik. Hal tersebut dikarenakan bias yang terbentuk relatif kecil $(<0,5 \%)$ (Liu dan Dong, 2015).

Sedangkan untuk pengukuran kualitas transmisi data melalui Bluetooth adalah dengan menggerakkan lengan meriam untuk 10 sudut berbeda dan diulang pada jarak yang berbeda sampai 10 meter. Hasil pengujiannya terlihat pada tabel 3 di bawah ini.
Tabel 3. Pengaruh Jarak Terhadap Sudut Terbentuk

\begin{tabular}{|c|c|c|c|c|c|c|c|c|c|c|c|}
\hline \multirow{2}{*}{ No } & Sudut & \multicolumn{10}{|c|}{ Sudut Terbentuk $\left(\alpha^{\prime}\right)$ pada Jarak $(\mathrm{m})$} \\
\cline { 3 - 12 } & $1 \mathrm{~m}$ & $2 \mathrm{~m}$ & $3 \mathrm{~m}$ & $4 \mathrm{~m}$ & $5 \mathrm{~m}$ & $6 \mathrm{~m}$ & $7 \mathrm{~m}$ & $8 \mathrm{~m}$ & $9 \mathrm{~m}$ & $10 \mathrm{~m}$ \\
\hline 1 & 10 & 10 & 10 & 10 & 10 & 10 & 10 & 10 & KT & KT & KT \\
\hline 2 & 30 & 30 & 30 & 30 & 30 & 30 & 30 & 30 & KT & KT & KT \\
\hline 3 & 45 & 45 & 45 & 45 & 45 & 45 & 45 & 45 & KT & KT & KT \\
\hline 4 & 60 & 60 & 60 & 60 & 60 & 60 & 60 & 60 & KT & KT & KT \\
\hline 5 & 90 & 90 & 90 & 90 & 90 & 90 & 90 & 90 & KT & KT & KT \\
\hline 6 & 120 & 120 & 120 & 120 & 120 & 120 & 120 & 120 & KT & KT & KT \\
\hline 7 & 135 & 135 & 135 & 135 & 135 & 135 & 135 & 135 & KT & KT & KT \\
\hline 8 & 150 & 150 & 150 & 150 & 150 & 150 & 150 & 150 & KT & KT & KT \\
\hline 9 & 165 & 165 & 165 & 165 & 165 & 165 & 165 & 165 & KT & KT & KT \\
\hline 10 & 180 & 180 & 180 & 180 & 180 & 180 & 180 & 180 & KT & KT & KT \\
\hline
\end{tabular}

Keterangan:

KT $=$ Komunikasi Terputus

Berdasarkan data yang diperoleh, diketahui bahwa sistem yang dikembangkan memiliki tingkat kepresisian yang tinggi pada sudut vertikal. Hal itu terlihat berdasarkan hasil pengukuran berulang yang dilakukan dengan perolehan hasil yang sama serta nilai $\overline{\boldsymbol{\sigma}}=0$. Adapun untuk arah horizontal nilai rata-rata kesalahannya adalah $\overline{\boldsymbol{\sigma}}=0.09$. Dengan kondisi tersebut, kedua arah lengan meriam dapat bekerja dengan sangat presisi (Cohen, 1998).

Dari data hasil pengukuran terlihat bahwa sampai dengan jarak 7 meter lengan meriam dapat membentuk sudut sampai $180^{\circ}$ dengan baik. Sedangkan untuk jarak lebih dari tujuh meter tidak ada komunikasi antara komputer dan perangkat.

\section{SIMPULAN}

Prototipe penentu sudut lengan meriam telah berhasil dikembangkan dengan teknologi pengendalian jarak jauh. Sistem yang dikembangkan memiliki tingkat akurasi rata-rata sudut vertikal diperoleh sebesar $0.2^{0}$, sedangkan sudut horizontal sebesar $0,4^{0}$ dengan kepresisian yang sangat baik yakni 0 untuk setiap sudut. Selain itu, 
perangkat ini dapat bekerja dengan jarak maksimum antara komputer dan perangkat sejauh 7 meter dengan tanpa penghalang

\section{DAFTAR PUSTAKA}

Abdullah, M., \& Budiman, M. (2011). Home-made PIC 16F877 microcontroller-based temperature control system for learning automatic control. Computer Applications in Engineering Education, 19(1), 10-17.

Cohen, E. R. (1998). An introduction to error analysis: The study of uncertainties in physical measurements.

Halliday, D., Resnick, R., \& Walker, J. (2010). Fundamentals of Physics, Chapters 33-37. John Wiley \& Sons.

Liu, J., \& Dong, Z. (2015, November). A design for high voltage DC power supply. In 2015 5th International Conference on Electric Utility Deregulation and Restructuring and Power Technologies (DRPT) (pp. 2227-2231). IEEE.

Melina, P. E., Witanti, W., \& Sukrido, K. V. (2020). Design and Implementation of Multi Knowledge Base Expert System Using the SQL Inference Mechanism for Herbal Medicine. In Journal of Physics: Conference Series (Vol. 1477, No. 2, pp. 1-9).

Morris, A. S. (2001). Measurement and instrumentation principles.

Ogata, K. (2001). PTR Upper Saddle River. Modern Control Engineering; Prentice-Hall: Upper Saddle River, NJ, USA.

Ruifeng, W., Zhe, W., \& Liying, W. (2015, June). Stepper Motor Control Based on AT89S51 Microcontroller. In 2015 8th International Conference on
Intelligent Computation

Technology and Automation (ICICTA) (pp. 844-847). IEEE.

Salam, R. A., Munir, M. M., Warsahemas, T., Saputra, C., Latief, H., \& Khairurrijal, K. (2019). A simple solar simulator with highly stable controlled irradiance for solar panel characterization. Measurement and Control, 52(3-4), 159-168.

Wu, M., \& Zhang, H. (2017, August). Design and Development of Circuit Board for Serial Interface Technology. In 2nd International Conference on Automatic Control and Information Engineering (ICACIE 2017) (pp. 26-30). Atlantis Press. 